Alma Mater Studiorum - Università di Bologna DEPARTMENT OF ECONOMICS

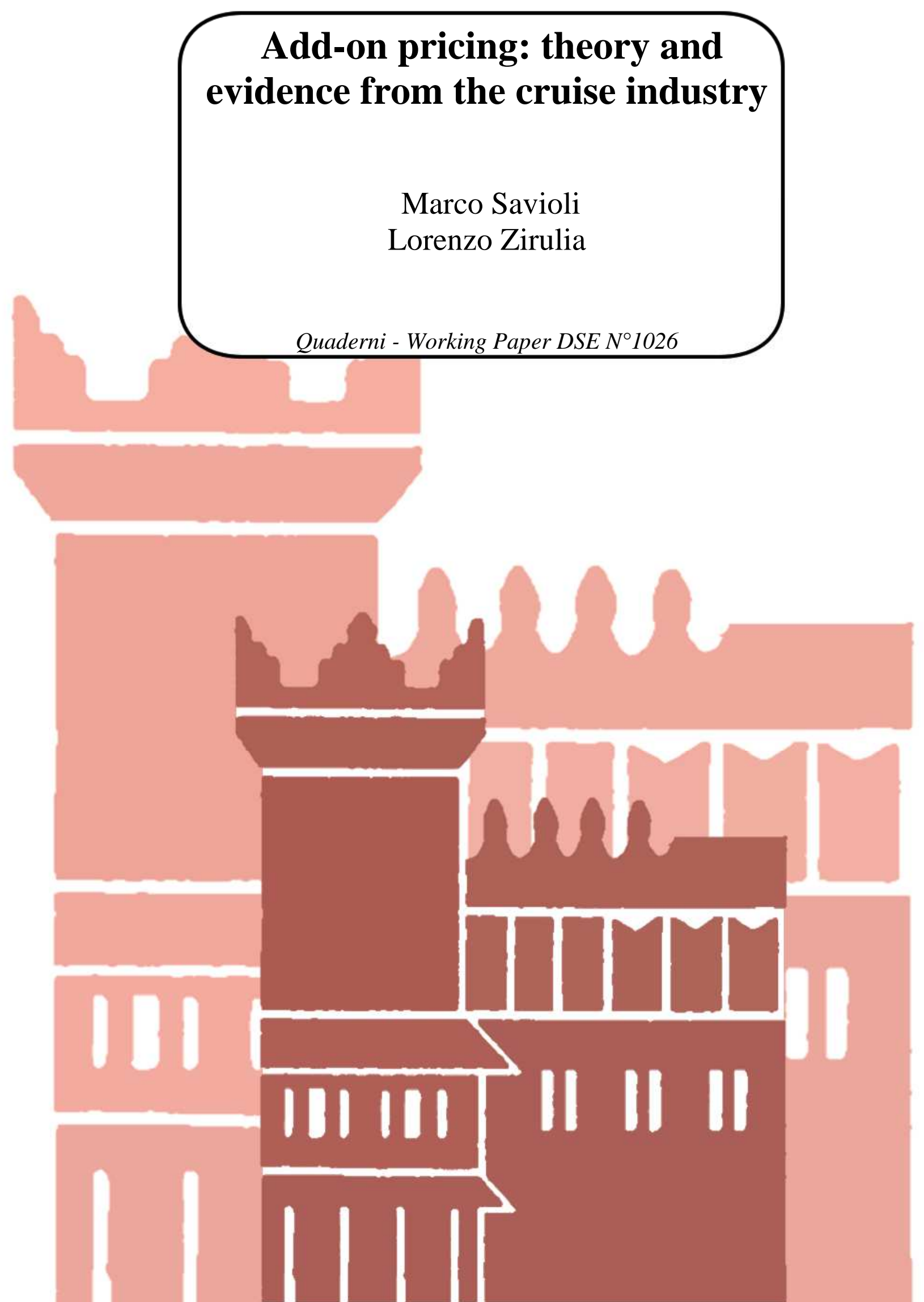




\title{
Add-on pricing: theory and evidence from the cruise industry
}

\author{
Marco Savioli` and Lorenzo Zirulia`
}

July 28, 2015

\begin{abstract}
In many industries, firms give consumers the opportunity to add (at a price) optional goods and services to a baseline product. The aim of our paper is to provide a theoretical model of add-on pricing in competitive environments with two new distinctive features. First, we discuss the choice of offering the add-on, assuming that this entails a fixed cost. Second, we allow firms to have a varying degree of market power over the add-on, associated with the ability to capture the value that consumers obtain from such an additional good/service. Our model shows that the conventional wisdom, according to which offering the add-on should unambiguously lower the price of the baseline product, is not always supported. In asymmetric equilibria, in which only one firm offers the add-on, baseline prices are higher if the firm's market power over the add-on is limited. The predictions of the model are confirmed by a hedonic price model on a dataset of cruises offered worldwide.
\end{abstract}

Keywords: Add-on pricing, Cruise industry, Hedonic regression

JEL classification: D43, L83

Acknowledgements: We wish to thank participants of the 2014 "Industrial Organization: Theory, Empirics and Experiment" Conference, University of Salento, the 2014 EARIE Conference, Bocconi University, Milan and the seminar at the Department of Economics, University of Bologna for their comments and suggestions. The usual caveat applies.

\footnotetext{
` Department of Economics, University of Bologna, Piazza Scaravilli 1 - 40126 Bologna, Italy and RCEA, Rimini, Italy. E-mail: m.savioli@unibo.it

^ Corresponding author. Department of Economics, University of Bologna, Piazza Scaravilli 1 - 40126 Bologna, CRIOS, Bocconi University, Milan, Italy and RCEA, Rimini, Italy. E-mail: lorenzo.zirulia@unibo.it
} 


\section{Introduction}

Add-ons, i.e. optional goods and services that consumers can add (at a price) to a baseline product, are ubiquitous. In the hotel industry, the price for a room typically does not include additional services such as telephone calls or minibar items. Similarly, airline tickets, especially in the case of low-cost carriers, do not include on-board meals. Appliance stores offer additional warranties to consumers after they buy. A long list of other examples could be provided. Often, prices for such add-ons are difficult (or costly) to observe before the baseline product is bought. This gives firms market power when selling add-ons even if the baseline product is offered in competitive markets. As a consequence, add-on prices tend to be high and firms compete on the baseline product price. This pricing scheme is the well-known "razor and blades" strategy, named after another typical example of a baseline product (i.e. the razor) and add-on (i.e. the blade).

The literature on add-on pricing is as rich as the business practice (Ellison, 2005; Gabaix and Laibson, 2006; Lal and Matutes, 1994; Verboven, 1999) focusing both on firms' strategy and the implications for antitrust and consumer policy (Shapiro, 1995; Gabaix and Laibson, 2006). Our focus being on the former, the first aim of our paper is to provide a theoretical model of add-on pricing in competitive environments with two distinctive features. First, we consider the choice of offering the add-on, assuming that this entails a fixed cost. Second, we allow firms to have varying degrees of market power over the add-on, associated with the ability to capture the value that consumers obtain from such additional goods.

The main result of our analysis is that the presence of add-ons does not necessarily lead to a lower price for the baseline product. On the one hand, when multiple firms offer add-ons, the price for the baseline product is lower compared to the case when add-ons are not offered. Moreover, the higher the market power over add-ons the lower the price for the baseline product. These results are intuitive and follow quite directly from the "razor and blades" 
argument. However, in asymmetric equilibria, in which only one firm offers the add-on, things change. The firm offering the add-on unambiguously obtains higher profits, but its price for the baseline product can be higher or lower depending on the degree of market power in the add-on market: baseline product prices are lower only when firms can extract ex-post a significant share of consumer surplus. Intuitively it can be argued on the one hand that the add-on provides higher utility to consumers, thus creating a competitive advantage for the firm offering it, which consequently can fix higher baseline product prices. On the other hand, the additional value that each consumer brings through the add-on leads to more aggressive pricing. The second effect prevails only if the proportion of surplus that the firm can appropriate is sufficiently large.

The predictions of the theoretical model are tested via a hedonic price function on a dataset of cruises offered worldwide. In the cruise industry, add-ons abound and the data show that the revenues associated with such add-ons are a fundamental source of profitability. However, add-ons differ with respect to the share of consumer surplus that can be captured by firms. In line with the model, as consumers have few alternatives while on board, we find those activities associated with on-board sales reducing cruise ticket prices. This is the case for casino and shops. However, as travellers can self-organise and other businesses can compete, market power is limited for shore excursions, for which we find a positive effect on price.

The rest of the paper is organised as follows. Section 2 reviews the theoretical and empirical literature on add-on pricing. The model is described and solved in Section 3 and its predictions are tested in Section 4. Section 5 provides further implications arising from our results. Finally, Section 6 concludes. 


\section{Literature review}

\subsection{The economics of add-ons: the theory}

The economic analysis of add-ons represents a quite consolidated stream of literature. A broad division can be made between contributions that posit consumers' full rationality and those, more recent, which rather assume bounded rationality and cognitive biases on the demand side.

One of the first contributions in the "full-rationality" camp is the work by Lal and Matutes (1994). The authors frame their problem in the context of loss-leader pricing, i.e. the strategy by which retailers advertise some good at a price below the marginal cost to attract customers and then make profits on other goods in store for which prices are not advertised. In their model, loss-leader pricing is an equilibrium when advertising costs are sufficiently large. Moreover, they formalise the so-called Chicago argument, in which the profit gain from the good sold at a high price (the add-on) simply compensates the loss on the advertised good (the baseline product). Another important early contribution is that by Verboven (1999), who develops a model in which firms offer baseline and premium products in a context of vertical and horizontal differentiation and consumers may have limited information on the prices for premium versions. More recently, Ellison (2005) has shown that the add-on pricing strategy (in which add-on prices are not observed) can indeed be profit-enhancing in a context in which the consumers' willingness to pay for the baseline product and the add-on are positively related. In this case, the large profit that firms obtain through the add-on from consumers with a high valuation for willingness to pay reduces the incentive to price the baseline product aggressively, which disproportionally attracts consumers with low willingness-to-pay valuations.

A related body of literature considers a foremarket for durable goods (e.g. printers, videogame consoles) and an aftermarket for non-durable goods and services (e.g. ink cartridges, spare 
parts, games). In this case, special attention is paid to antitrust policy implications for firms' market power over the aftermarket when the foremarket is competitive but consumers are locked in after buying, in particular following the well-known Kodak case (Shapiro, 1995). While firms' incentive to sell above the marginal cost in the aftermarket and at a low price (possibly below cost) in the foremarket is a common finding (Borenstein et al., 2000), the social evaluation of this outcome has been debated. Some inefficiencies due to above-cost pricing in the aftermarket, such as the excessive cost of replacement of durable goods, may have a small impact when the reduced price in the foremarket is taken into account (Shapiro, 1995). In other cases, as when the aftermarket is characterised by increasing returns, market power over the aftermarket can instead be beneficial in terms of social and possibly consumer surplus (Cabral, 2014). ${ }^{1}$ On the other hand, aftermarket rents and aggressive pricing in the foremarket may lead to inefficient outcomes (in terms of profits and consumer and social welfare) if there are consumers whose willingness to pay for the base good is lower than cost (Zegners and Kretschmer, 2014).

The departure from consumers' full rationality is the starting point of more recent contributions in the add-on literature. The seminal paper by Gabaix and Laibson (2006) looks at incentives for firms to "shroud" information on add-on prices. They consider the coexistence of myopic consumers, who consider the add-on only if information on its existence and its price is "unshrouded", and sophisticated consumers, who rationally predict add-on prices when information is shrouded and can avoid a (costly) purchase if they expect the addon price to be too high. The authors find that if the share of myopic consumers is sufficiently large, shrouding equilibria (in which firms adopt an add-on pricing strategy) are possible, even if unshrouding is costless. In this case, myopic consumers are worse off (because of the high price of the add-on) and sophisticated consumers are better off (because they can take

\footnotetext{
${ }^{1}$ Carlton and Waldman (2009) identify other mechanisms through which aftermarket monopolisation can be efficiency enhancing.
} 
advantage of a low base price and avoid the high-price add-on). ${ }^{2}$ The model has been extended in several directions, analysing for instance the role of competition in unshrouding information (Wenzel, 2014), the case of asymmetric firms (Shulman and Geng, 2012), or identifying the conditions under which high add-on prices may also benefit myopic consumers (Zenger, 2013).

With respect to the existing literature, in most of our analysis we adopt a full rationality approach. Therefore, unsurprisingly we find an irrelevance result for the add-on pricing strategy in terms of profits, along the lines of Lal and Matutes (1994) and consistent with the Chicago view. However, we contribute to the literature in two particular ways: first by making the decision to offer the add-on endogenous and allowing for different degrees of market power when supplying the add-on; second by focusing on the relationship between the degree of market power in the add-on market and the price of the baseline product in symmetric and asymmetric situations. Our modelling framework is similar to that of Zegners and Kretschmer (2014), in particular in the way they represent market power for add-ons. However, on the one hand, they explicitly consider the presence of low valuation consumers who do not buy the add-on, which we do not have and which is the key element through which aftermarket power can backfire; on the other hand, they do not consider the decision of firms to offer the add-on, which is an important ingredient in our model as the relationship between the degree of market power in the add-on market and the price of the baseline product differ between symmetric and asymmetric situations.

\subsection{The economics of add-ons: the empirical evidence}

Pricing strategies involving add-ons have also been investigated in a wide array of empirical studies. In the older literature, Walters and MacKenzie (1988) find that loss leader pricing has no effect on profit in the case of two US supermarket chains, thus confirming the Chicago

\footnotetext{
${ }^{2}$ In Gabaix and Laibson (2006), competition always leads to zero profits for firms.
} 
view. Verboven (1999) tests his model against data from the automobile market and finds that in the low-class part of the market, where brand rivalry is intense, only the model with limited information on the prices for premium versions (add-ons) can account for their larger percentage mark-ups.

More recent empirical works are in general more favourable to the idea of add-on pricing strategy profitability. By using field and natural experiments in online auctions, Brown et al. (2010) find that firms enjoy higher revenues by increasing hidden charges. Based on a field experiment in a large Turkish bank, Alan et al. (2015) find that SMS messages announcing a large discount on overdraft interest rates reduce overdraft usage, while those messages that mention overdraft availability without referring to prices increase it. Therefore, firms lack incentives to draw attention to or otherwise compete on prices of overdrafts (an add-on for banks). Ellison and Ellison (2009) provide further evidence on the profitability of add-on pricing as an obfuscation strategy frustrating consumer search. Furthermore, consumers are found to underreact to monetary costs that are not salient, as shown by Chetty et al. (2009) when looking at the effect on demand when taxes are not included in the price. However, Hartmann and Nair (2009) find that manufacturers may profitably shift margins between the primary and aftermarket good, but cannot exploit customers in the aftermarket without suffering decreased primary good adoption. ${ }^{3}$

In line with the theoretical model, on the empirical side we are not interested in evaluating the impact of add-on pricing on profits, but rather we start from the observation that in our empirical context, i.e. the cruise industry, we do observe add-on pricing. Instead, we test our theory by estimating a hedonic price function in a novel ideal setting: on cruises. By estimating a hedonic price function for this controlled environment, we can differentiate the

\footnotetext{
${ }^{3}$ Also, there are a few laboratory experimental papers on add-ons (Normann and Wenzel, 2013) and the related issue of product attribute complexity and buyer confusion (Kalayc1 and Potters, 2011).
} 
estimated effects on baseline product price for add-on (characteristics) endowed with different measures of firms' market power.

\section{The model}

In this section, the model is described (Section 3.1) and solved (Section 3.2). Particular attention is paid to the relationship between the baseline product price and the degree of addon surplus appropriability (market power), which is tested in Section 4. In Section 3.3 we extend the model in two directions: first, we allow firms to bundle the baseline product and the add-on; second, we introduce consumers' biased beliefs, through which the profit equivalence between the add-on pricing strategy and bundling no longer holds.

\subsection{Model description}

Two firms compete. Each firm offers a baseline product, denoted B, for which it may offer an add-on A. Each consumer buys at most one unit of B and A. Moreover, consumers can buy A only from the firm from which they bought product B.

Baseline products are horizontally differentiated. Horizontal differentiation is captured by assuming the existence of a standard Hotelling segment of unit length, where firms are located at the extremes ( 0 and 1$)$ and a unit mass of consumers is uniformly distributed along the segment $\left(x_{i}\right.$ is the location of the generic consumer $\left.i\right)$. We will refer to firms as firm 0 and 1 based on their location. The gross surplus generated by the baseline product is $u^{B}$, the unit cost of production for B is 0 , while the outside option value of not buying is also normalised to 0 . If firms offer the baseline product only, the utility of consumer $i$ buying from firms 0 and 1 is respectively given by:

$$
\begin{aligned}
& u_{i}(0)=u^{B}-p_{0}^{B}-t x_{i} \\
& u_{i}(1)=u^{B}-p_{1}^{B}-t\left(1-x_{i}\right)
\end{aligned}
$$


where $p_{0}^{B}$ and $p_{1}^{B}$ are the prices for the baseline product and $t>0$ is a standard "transport cost" parameter inversely related to the intensity of price competition. We shall assume that the market is covered, which is guaranteed if $u^{B}$ is sufficiently large.

Consumers' preferences for the add-on are homogeneous. If a firm offers A, the gross surplus the consumer obtains from $\mathrm{A}$ is $u^{A}$, with the unit cost for producing $\mathrm{A}$ also nil. In a reducedform approach, we shall assume that the firm has a limited ability to appropriate consumer surplus from the add-on, denoting as $\alpha(0 \leq \alpha \leq 1)$ the share of the consumer surplus that accrues to the firm. Thus, $\alpha$ also stands for the degree of a firm's market power. Let $p_{0}^{A}$ and $p_{1}^{A}$ denote the prices for product $\mathrm{A}$ offered by firms 0 and 1 , respectively: this implies that $p_{0}^{A}=p_{1}^{A}=\alpha u^{A}$. Moreover, a firm deciding to offer A incurs a fixed cost $k .^{4}$

A few examples can clarify the kind of situations our model aims to represent:

1. Consider the case of the cruise industry, investigated in the empirical part and thus discussed more at length in Section 4. Examples of add-ons are casinos and other on-board activities (e.g. spa, shops, etc.) and shore excursions. For on-board activities, offering such add-ons may entail a fixed cost in terms of physical investment and dedicated personnel. When the opportunities for shore excursions increase by adding intermediate ports to the itinerary (or ports of call, as they are known), firms incur dockage and other service fees at the port. In the case of on-board activities, we can expect a high value of $\alpha$ as consumers have few available alternative options in this case. In the case of shore excursions, however, travellers may opt for self-organised trips or specialised tour-operators. Still, it is the decision of the cruise company to add an intermediate port that allows consumers to obtain this positive surplus.

\footnotetext{
${ }^{4}$ As we do not model the decision as to whether or not to offer the baseline product, the fixed cost associated with this decision is not considered.
} 
2. Consider the case of razors. In this case, the add-on is given by replacement blades and the surplus appropriability depends on the degree of compatibility between the heads of razors and non-proprietary blades. Still, it is the decision of the firm to offer a non-disposable razor that allows consumers to appropriate part of the surplus.

3. Finally, consider the case of printers. The add-on is given by the option for consumers to replace a used-up cartridge. In this case, independent producers' cartridges may limit the market power of the printer manufacturer; once again, it is the decision of the firm to offer non-disposable printers guaranteeing users part of the surplus.

The examples stress an important feature of our model, i.e. that add-ons are valued by consumers. This is contrast to most of the recent literature, which focuses on add-ons that represent utility reductions which consumers can avoid at a cost (Gabaix and Laibson, 2006).

As further remark, we can also observe that our model turns out to be equivalent to a few instances in which consumers are (ex-ante or ex-post) heterogeneous with respect to add-on surplus. In particular:

- Suppose there are two types of consumers: a type with $u^{A}>0$ (associated with a value $\alpha$ ) and a type with $u^{A}=0$. There is a probability $\rho$ that a consumer is type- $u^{A}$ (independent of consumers' horizontal preferences), while with the remaining probability is type- 0 . The type is known to consumers but unobservable by the firm. It can be shown that this model is equivalent to the basic version of the model if we define $u^{\prime A}=\rho u^{A}$.

- In the two-type model just described, let us assume that individual consumers are exante uncertain of their own type, which they discover after buying the baseline product. The consumer is type- $u^{A}$ with probability $\lambda$. In this case, the model is equivalent to the basic version redefining $u^{\prime A}=\lambda u^{A}$. 
If firms offer the add-on, then the utility of consumer $i$ buying from firms 0 and 1 is given respectively by:

$$
\begin{aligned}
& u_{i}(0)=u^{A}-p_{0}^{A}+u^{B}-p_{0}^{B}-t x_{i} \\
& u_{i}(1)=u^{A}-p_{1}^{A}+u^{B}-p_{1}^{B}-t\left(1-x_{i}\right)
\end{aligned}
$$

As for the timing of the game, we consider a three-stage game, which is relevant when firms adopt what we label the add-on pricing strategy:

- At $t=0$, firms simultaneously decide whether to offer add-on A or not.

- At $t=1$, firms simultaneously post their prices for B, having observed the decisions of both firms at $t=0$.

- At $t=2$, firms decide their prices for product $\mathrm{A}$, in the case it is offered.

Some observations are in order. First, we assume that consumers are forward-looking in that they correctly anticipate the decision taken by each firm at $t=2$ when deciding from which firm to buy at $t=1$. We relax this assumption in Section 3.3.1, allowing for consumers with biased beliefs. Second, the assumption that the price for product $\mathrm{A}$ is fixed at $t=2$ is equivalent to assuming that the firms cannot commit to future prices. We also analyse in Section 3.3.1 what happens when firms can commit by selling A and B in a single bundle.

\subsection{Model solution}

As usual in multi-stage games with complete information, the relevant solution concept is subgame perfection. As a matter fact, we have already solved stage 2 by assuming that add-on prices (if the add-on is offered) are $p_{0}^{A}=p_{1}^{A}=\alpha u^{A}$. So, what remain to be solved are stage 1 (Section 3.2.1) and stage 0 (Section 3.2.2). 


\subsubsection{Pricing the baseline products: firms' behaviour at $\mathrm{t}=1$}

At $t=1$, both firms and consumers correctly predict the outcome at $t=2$. From the point of view of consumers, if the firms offer A, the utility functions that are used to compare the two firms' offers are obtained by putting $p_{0}^{A}=p_{1}^{A}=\alpha u^{A}$ into (3) and (4), yielding:

$$
\begin{aligned}
& u_{i}(0)=(1-\alpha) u^{A}+u^{B}-p_{0}^{B}-t x_{i} \\
& u_{i}(1)=(1-\alpha) u^{A}+u^{B}-p_{1}^{B}-t\left(1-x_{i}\right)
\end{aligned}
$$

while equations (1) and (2) are the relevant ones when A is not offered.

For the analysis of firms' behaviour at stage $t=1$, four cases must be considered: a) no firm offers A; b) only firm 0 offers A; c) only firm 1 offers A; d) both firms offer A.

The following proposition reports equilibrium prices for B and equilibrium profits for the four cases (proofs are in Appendix A).

Proposition 1. Equilibrium prices for $B$ and equilibrium profits can be summarised as follows: $:^{5}$

a) If no firm offers $A$, then $p_{0}^{B}=p_{1}^{B}=t$ and $\Pi_{0}(i)=\Pi_{1}(i)=\frac{t}{2}$

b) If only firm 0 offers $A$, then $p_{0}^{B}=t+\frac{u^{A}}{3}[1-3 \alpha], p_{1}^{B}=t-\frac{u^{A}}{3}$ and

$$
\Pi_{0}(i i)=\left(t+\frac{u^{A}}{3}\right)\left(\frac{1}{2}+\frac{u^{A}}{6 t}\right)-k \text { and } \Pi_{1}(i i)=\left(t-\frac{u^{A}}{3}\right)\left(\frac{1}{2}-\frac{u^{A}}{6 t}\right)
$$

c) If only firm 1 offers $A$, then $p_{1}^{B}=t+\frac{u^{A}}{3}(1-3 \alpha), p_{0}^{B}=t-\frac{u^{A}}{3}$ and

$$
\Pi_{1}(i i i)=\left(t+\frac{u^{A}}{3}\right)\left(\frac{1}{2}+\frac{u^{A}}{6 t}\right)-k \text { and } \Pi_{0}(i i i)=\left(t-\frac{u^{A}}{3}\right)\left(\frac{1}{2}-\frac{u^{A}}{6 t}\right)
$$

d) If both firms offer $A$, then $p_{0}^{B}=p_{1}^{B}=t-\alpha u^{A}$ and $\Pi_{0}(i v)=\Pi_{1}(i v)=\frac{t}{2}$

\footnotetext{
${ }^{5}$ We shall assume that $t>\frac{u^{A}}{3}$, which guarantees positive profit in the asymmetric configurations also for the firm offering the baseline product only.
} 
Proposition 1 suggests a number of considerations. First, by comparing cases $a$ ) and $d$ ), we notice that when both firms offer the add-on, profits do not change with respect to the case in which the add-on is not offered: firms remain symmetric (each obtaining half of the market) and the price of the baseline product is reduced by an amount exactly equal to the price of the add-on. This effect mimics well-known irrelevance results present in the literature (Lal and Matutes, 1994): when product A is offered, each consumer is more valuable (because he or she yields an additional profit $\alpha u^{A}$ ) and this leads firms to compete more aggressively on the baseline product.

Second, interesting insights come from comparing the strategies of firms that offer the add-on to those of firms that do not. Consider the case in which only one firm offers the add-on, say firm 0 (case b), and compare it with the case in which no firm offers the add-on (case a). We observe that in case b) firm 0 posts a higher price if $\alpha<1 / 3$ and a lower price otherwise. Firm 1 , instead, unambiguously fixes a lower price. The intuition underlying this result goes as follows. From the point of view of firm 0, offering the add-on has two effects. On the one hand, by providing higher utility to consumers (compared to firm 1), firm 0's demand increases, thus making higher prices more attractive. The lower $\alpha$, the greater this effect, i.e. the larger is the proportion of the surplus that the consumer can appropriate. On the other hand, the additional value that each consumer brings through the add-on leads to more aggressive pricing. Here, the larger $\alpha$, the greater this effect, i.e. the larger is the proportion of the surplus that the firm can appropriate. When $\alpha$ is sufficiently low, the first effect prevails and consequently the firm offering the add-on posts a higher price. Firm 1, instead, reduces its price because its product becomes relatively less attractive.

Similar insights drive the comparison of prices by firm 0 and firm 1 in case $b$, for which we obtain: 


$$
p_{0}^{B}-p_{1}^{B}=\frac{u^{A}}{3}(2-3 \alpha)
$$

i.e. firm 0 posts a higher price if $\alpha<2 / 3$ and a lower price otherwise. When the firm can appropriate a large surplus from the add-on, it has strong incentives to reduce its price to attract additional consumers; if it cannot, it can take advantage of larger demand for its product by raising its price.

In Figure 1, we compare the equilibria in cases $a$ ) and $b$ ) above in two possible situations. In situation (i), $\alpha$ is "low" $(\alpha<1 / 3)$, so that the price fixed by the firm offering the add-on in the asymmetric equilibrium is higher than the price in a symmetric equilibrium without add-ons. In situation (ii), $\alpha$ is "high" $(\alpha>2 / 3)$, so that in the asymmetric equilibrium the price fixed by the firm offering the add-on is lower than the competitor's price. Firms' best responses are drawn using a dashed line for case $a$ ) and a solid line for case $b$ ).

Figure 1 - Offering the add-on: the impact on prices
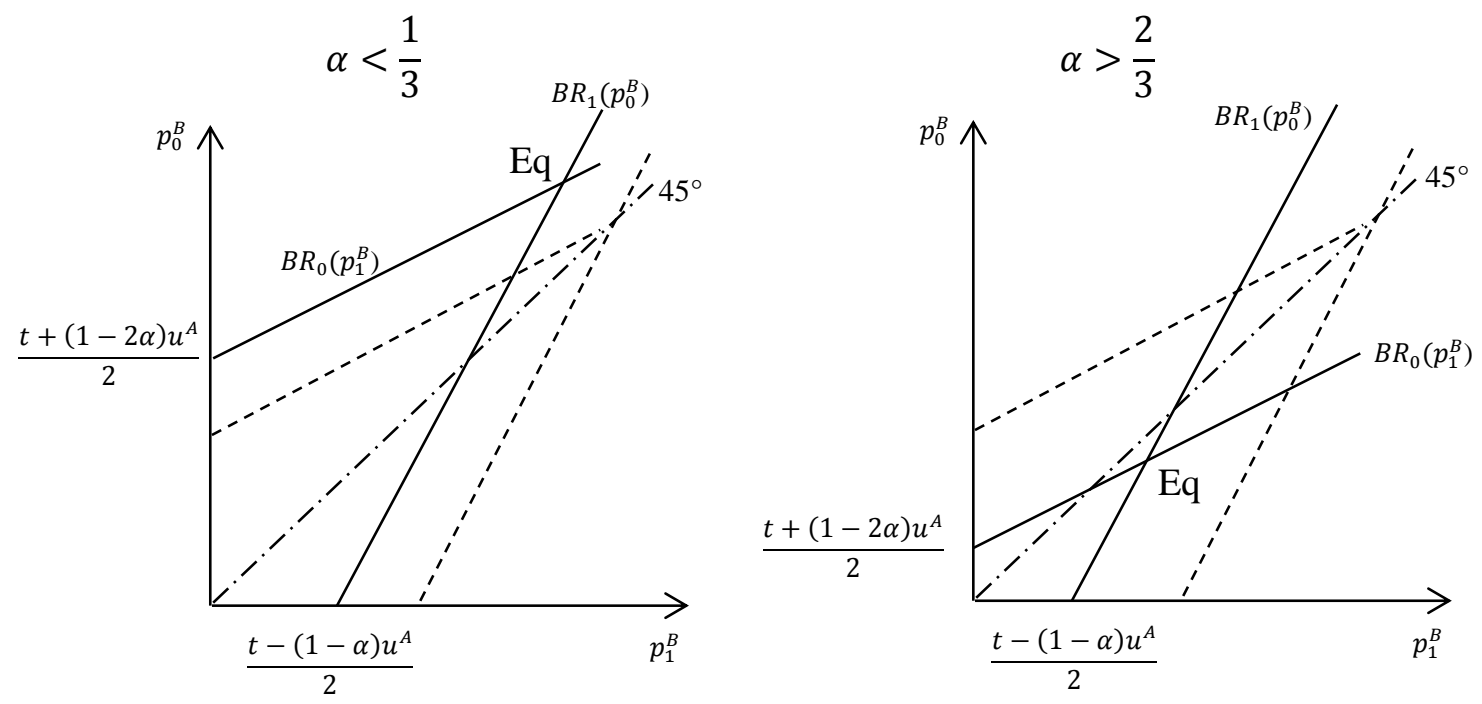

\subsubsection{Choosing whether to offer the add-on: firms' behaviour at $\mathbf{t}=\mathbf{0}$}

At $t=0$, firms must choose simultaneously whether to offer the add-on A at a common fixed cost $k$ (action OffA) or not (action NotOffA). By applying subgame perfection, at this stage we 
need to solve a $2 \times 2$ game, the payoffs of which are computed using profit levels determined in the previous subsection. The payoff matrix is represented in Table 1.

Table 1 - Game at $\mathrm{t}=0$

\begin{tabular}{|c|c|c|}
\hline Firm O\Firm 1 & NotOffA & OffA \\
\hline NotOffA & $\Pi_{0}(i) ; \Pi_{1}(i)$ & $\Pi_{0}(i i i) ; \Pi_{1}(i i i)-k$ \\
\hline OffA & $\Pi_{0}(i i)-k ; \Pi_{1}(i i)$ & $\Pi_{0}(i v)-k ; \Pi_{1}(i v)-k$ \\
\hline
\end{tabular}

The Nash equilibria of the game represented in Table 1 coincide with the subgame perfect equilibria (SPE) of the overall game and are summarised in Proposition 2 (proof in Appendix A).

Proposition 2. The subgame perfect equilibria are determined as follows:

1. If $k<\frac{1}{2} t-\left(t-\frac{u^{A}}{3}\right)\left(\frac{1}{2}-\frac{u^{A}}{6 t}\right)$, the SPE is such that at $t=0$ both firms choose OffA.

2. If $\frac{1}{2} t-\left(t-\frac{u^{A}}{3}\right)\left(\frac{1}{2}-\frac{u^{A}}{6 t}\right)<k<\left(t+\frac{u^{A}}{3}\right)\left(\frac{1}{2}+\frac{u^{A}}{6 t}\right)-\frac{1}{2} t$, there are two SPE such that at $t=0$ one firm only chooses OffA.

3. If $k>\left(t+\frac{u^{A}}{3}\right)\left(\frac{1}{2}+\frac{u^{A}}{6 t}\right)-\frac{1}{2} t$, the unique SPE is both firms choosing NotOffA.

The interpretation of Proposition 2 is straightforward. Whenever $k$ is large (case 3), firms prefer not to offer the add-on A. If $k$ is low, both firms offer A. Note that in this case firms are in fact "entrapped" in a prisoner's dilemma situation. Although for both firms it is individually rational to offer A, firms would be jointly better off by not offering A. Finally, for intermediate values of $\mathrm{A}$, asymmetric equilibria emerge in which only one firm offers A. For this outcome to be an equilibrium, it must be $\left(t+\frac{u^{A}}{3}\right)\left(\frac{1}{2}+\frac{u^{A}}{6 t}\right)-k>\frac{1}{2} t>\left(t-\frac{u^{A}}{3}\right)\left(\frac{1}{2}-\frac{u^{A}}{6 t}\right)$, which implies that the firm offering the add-on obtains higher profit. 


\subsection{Extensions}

\subsubsection{Extension I: the bundling case}

In our empirical exercise, some add-ons are offered for free (in fact, their price is included in the baseline product price). For that reason, it is important to make a prediction regarding the relationship between offering this kind of add-on and the baseline product price.

Suppose that the firm offering an add-on can commit to its future price, or equivalently in our framework, it can sell the bundle $\mathrm{A}+\mathrm{B}$ at the price $p^{A B}$, fixing the price at $t=1$. In the symmetric case in which both firms offer the add-on, utility is given by:

$$
\begin{aligned}
& u_{i}(0)=u^{A}+u^{B}-p_{0}^{A B}-t x_{i} \\
& u_{i}(1)=u^{A}+u^{B}-p_{1}^{A B}-t\left(1-x_{i}\right)
\end{aligned}
$$

It can immediately be seen that the demand functions in this case are equivalent to case a) described in Section 3.2.1 and so prices are $p_{0}^{A B}=p_{1}^{A B}=t$, yielding $\Pi_{0}^{*}=\Pi_{1}^{*}=\frac{t}{2}$.

The asymmetric case, in which firm 0 offers the bundle $A+B$ and firm 1 offers $B$ only, yields the following utility functions:

$$
\begin{aligned}
& u_{i}(0)=u^{B}+u^{A}-p_{0}^{A B}-t x_{i} \\
& u_{i}(1)=u^{B}-p_{1}^{B}-t\left(1-x_{i}\right)
\end{aligned}
$$

Again, this case is isomorphic to case b) in Section 3.2.1 with $\alpha=0$. Therefore, equilibrium prices are $p_{0}^{A B}=t+\frac{u^{A}}{3}$ and $p_{1}^{B}=t-\frac{u^{A}}{3}$. The first implication of this result is that when firms can commit (bundle), adding A has an unambiguously positive impact on the (single) price posted by the firm, which comes from the higher quality offered by the firm.

As for the second implication, we observe that if firm 0 offers the add-on through the add-on pricing strategy, it obtains a total price equal to $p_{0}^{B}+p_{0}^{A}=t+\frac{u^{A}}{3}(1-3 \alpha)+\alpha u^{A}=t+\frac{u^{A}}{3}$. Therefore, 
we obtain a second irrelevance result: bundling has no effect on the total price paid and consequently on profits. This implies that the model in its present form cannot account for the decision to bundle B and A or to use an add-on pricing strategy instead. While modelling this decision is not at the core of our paper, in the following section we briefly describe an extension with consumer biased beliefs which provides a possible answer to this issue.

\subsubsection{Extension II: consumer biased beliefs}

In the basic version of the model, firms and consumers base their decision on the same proportion of add-on surplus appropriated by the firm $(\alpha)$. This implies a profit equivalence between adopting the add-on strategy and bundling. We shall now assume that the proportion relevant to firms $(\alpha)$ and the proportion relevant to consumers $(\gamma)$ may differ. Following the industrial organization literature with boundedly rational consumers (Spiegler, 2011), we interpret $\alpha$ as the actual value and $\gamma$ as the value perceived by the consumer. It follows that $\alpha>\gamma$ can be interpreted as consumer over-optimism in that consumers may underestimate the price paid or overestimate the surplus from the add-on. ${ }^{6} \alpha<\gamma$, instead, may occur if consumers are overly pessimistic, or ex-ante uncertain about the surplus they will obtain from the add-on and they overestimate the probability to assign a positive value.

Focusing on the asymmetric case in which firm 0 offers the add-on, the firms' best response functions become:

$$
\begin{aligned}
& p_{0}^{B}=\frac{t+p_{1}^{B}+(1-\alpha-\gamma) u^{A}}{2} \\
& p_{1}^{B}=\frac{t+p_{0}^{B}-(1-\gamma) u^{A}}{2}
\end{aligned}
$$

Solving the system (12)-(13) yields the equilibrium prices:

$$
p_{0}^{B}=t+\frac{u^{A}}{3}(1-2 \alpha-\gamma)
$$

\footnotetext{
${ }^{6}$ Zenger (2013) makes a similar assumption.
} 


$$
p_{1}^{B}=t-\frac{u^{A}}{3}(1+\alpha-\gamma)
$$

For the firm offering the add-on, the equilibrium profit is:

$$
\left[t+\frac{u^{A}}{3}(1+\alpha-\gamma)\right]\left[\frac{1}{2}+\frac{u^{A}}{6 t}(1+\alpha-\gamma)\right]-k
$$

For the firm offering a bundle of $\mathrm{A}$ and $\mathrm{B}$ (competing with a firm offering $\mathrm{B}$ only), the equilibrium profit is:

$$
\left(t+\frac{u^{A}}{3}\right)\left(\frac{1}{2}+\frac{u^{A}}{6 t}\right)-k
$$

Comparing (16) and (17), it transpires that the add-on pricing (bundling) strategy is advantageous if $\alpha>\gamma(\alpha<\gamma)$. If the consumer is over-optimistic, the firm can use the addon strategy both to attract consumers via higher expected net surplus and to attain ex post additional profit.

\section{Empirical validation}

In this section, we estimate a hedonic price function that permits empirical validation of the theoretical results. A dataset of cruises offered worldwide, described in the following subsection, allows us to determine whether and how the ticket prices observed on the market are affected by the add-ons, controlling for other relevant cabin, ship and trip characteristics of a cruise.

\subsection{Data}

The cruise industry is among the fastest growing categories in the entire leisure market. From 1970 to 2004, the number of passengers increased by 2200\% (Klein, 2006). Even in recent years, despite the economic crisis, the number of passengers increased from 18.7 million to 21.3 million between 2010 and $2013 .^{7}$ As it has grown, the industry has also consolidated.

\footnotetext{
${ }^{7}$ Source: Cruise Lines International Association.
} 
Now, the top three cruise companies, i.e. the Carnival Corporation, Royal Caribbean Cruises Ltd. Co. and Norwegian Cruise Line Holdings Ltd., account for $79.4 \%$ of the worldwide share of carried passengers and $71.8 \%$ of the worldwide share of revenues. ${ }^{8}$ Meanwhile, a tendency to reduce ticket prices has been observed, transforming a cruise from a luxury product into a mass product. At the same time, profitability has been preserved thanks to economies of scale guaranteed by mega ships, savings in labour costs, offshore registrations and the emergence of new extra-ticket revenue centres (Klein, 2006). Nowadays, a cruise ship can be considered a "floating resort" as it includes all the facilities and activities of a tourism destination and the data show that extra revenues associated with such add-ons are the main source of profitability for firms (Vogel, 2011, 2009).

To test the predictions of the model empirically, we use observations on 2072 cruises offered worldwide in the period July-August 2013. All the data in our sample were collected on line in April 2013 through the website Cruise.com. Table B1 in

\footnotetext{
${ }^{8}$ http://www.cruisemarketwatch.com/
} 
Appendix B provides descriptive statistics.

Price per night, the dependent variable of the regression model, was the cheapest offer at that time for each cabin type; it is expressed as the entire (port charges included) US\$ price per person without taxes divided over the trip's number of nights. The other data can be grouped into three sets of variables: cabin, ship and trip characteristics.

The cabin characteristics comprise the following categories: inside cabin, ocean view (not obstructed) cabin, balcony cabin and suite. Within the set of cabin characteristics, the only numerical variable is the cabin square footage expressed in square feet. All the remaining variables (private bath, air conditioning, refrigerator, individual safe, TV, music console, telephone and hair dryer) are dummies for the presence of that characteristic inside the cabin.

The many characteristics pertaining to the ship are also registered through dummies (laundry, swimming pool, beauty salon, casino, fitness, jogging track, boutiques, Wi-Fi, library and spa). The age of the ship is expressed in years, the capacity in number of passengers and the speed in nodes.

The last set of variables groups the trip characteristics. In addition to the number of nights of the trip, the variable excursions per night was obtained by dividing the number of intermediate ports on the itinerary by the number of nights. The two categorical variables destination and cruise line produce a large set of dummies to control for their effect on the price per night.

\subsection{Model specification and hypotheses}

In the next section, an hedonic price model is estimated (Rosen, 1974), in which we measure the relative impact on prices of all the cruise's characteristics. Eleven of these characteristics are in fact add-ons to the baseline product, while the other cabin, ship and itinerary 
characteristics are used as controls. ${ }^{9}$ Therefore, the estimated coefficient for an add-on represents the effect on prices of offering a certain add-on, ceteris paribus. It follows that the relevant theoretical predictions are those concerning the effects on price following the inclusion of an add-on by a single firm.

Based on the literature (Klein, 2006) and online guides for first-time travellers, ${ }^{10}$ we can classify add-ons into three groups: i) add-ons for which the degree of consumer surplus appropriability $\alpha$ is high; ii) add-ons for which the degree of consumer surplus appropriability $\alpha$ is low; iii) add-ons which are included in the price of the baseline product.

- Casino gaming, boutiques, spa treatments, beauty salons, Wi-Fi and laundry services are add-ons typically not included in the ticket price, for which the firms' market power is expected to be high as they are offered on board. Therefore, we expect a negative effect on the cruise ticket price.

- Shore excursions are other add-ons not included in the ticket price. In this case, however, we argue that the degree of firm market power is limited: we expect a positive coefficient for the variable number of excursions in our regression.

- Finally, if the add-on is included in the ticket price, we expect (see Section 3.3.1) the sign for the ticket to be positive. This is the case for a swimming pool, fitness centre, jogging track and library. ${ }^{11}$

\footnotetext{
${ }^{9}$ Including the latter is very important for the estimated models as it corrects for possible omitted variables that are constant over destinations and lines.

10 See, for instance, websites such as http://www.cruises.com/promotion/cruising-101.do or http://www.cruise.com/cruise-information/cruise-tips.asp

${ }^{11}$ In principle, the coefficients in the hedonic regression account for both the impact on consumer valuation and marginal cost. This could be problematic for those variables (add-ons) for which we expect a positive coefficient. In the case of excursions (number of intermediate ports in the itinerary), marginal cost is affected by a per passenger fee levied by ports. However, strong competition among ports to attract visitors has usually kept these fees at a very low level (Klein, 2006).
} 


\subsection{Estimates}

Before estimating the model, we transform numerical variables into natural logarithms. ${ }^{12}$

Table 2 reports the results of two OLS estimations: the first model is complete and the second model is more parsimonious. ${ }^{13}$ At the end of the table, diagnostic tests are reported. The high significance of the regression tests and the high adjusted $\mathrm{R}^{2}$ allow us to conclude that these models explain cruise pricing fairly well. Finally, the last three tests show that neither model suffers from problems of collinearity, a misspecified functional form or heteroscedasticity.

Table 2 - Hedonic price model estimations

\begin{tabular}{|c|c|c|c|c|}
\hline \multirow{2}{*}{$\begin{array}{l}\text { Dependent Variable: Price per night (log of) } \\
\text { Explanatory Variables: }\end{array}$} & \multicolumn{2}{|c|}{ Complete model } & \multicolumn{2}{|c|}{ Parsimonious model } \\
\hline & Coefficient & Standard Error & Coefficient & Standard Error \\
\hline & \multicolumn{4}{|c|}{ Add-ons } \\
\hline Laundry & -0.009 & $(0.024)$ & & \\
\hline Swimming pool & -0.059 & $(0.075)$ & & \\
\hline Beauty salon & -0.037 & $(0.025)$ & $-0.042 *$ & $(0.024)$ \\
\hline Casino & $-0.285^{* * *}$ & $(0.043)$ & $-0.283 * * *$ & $(0.042)$ \\
\hline Jogging track & $-0.040 * *$ & $(0.017)$ & $-0.033 * *$ & $(0.017)$ \\
\hline Boutiques & $-0.040 * *$ & $(0.018)$ & $-0.044 * *$ & $(0.018)$ \\
\hline Wi-Fi & $-0.105^{* * *}$ & $(0.015)$ & $-0.106^{* * *}$ & $(0.015)$ \\
\hline Library & $0.045^{* *}$ & $(0.021)$ & $0.051 * *$ & $(0.021)$ \\
\hline Spa & $0.136 * * *$ & $(0.041)$ & $0.127 * * *$ & $(0.041)$ \\
\hline Fitness & $0.035^{*}$ & $(0.019)$ & $0.033^{*}$ & $(0.019)$ \\
\hline \multirow[t]{2}{*}{ Excursions per night (log of) } & $0.026^{* * *}$ & $(0.006)$ & $0.028 * * *$ & $(0.006)$ \\
\hline & \multicolumn{4}{|c|}{$\begin{array}{c}\text { Controls } \\
\text { Cabin characteristics }\end{array}$} \\
\hline Cabin type (Inside cabin reference category) & \multicolumn{2}{|c|}{$F(3,1993)=529.00^{* * *}$} & \multicolumn{2}{|c|}{$F(3,2011)=547.54 * * *$} \\
\hline Ocean view cabin & $0.196^{* * *}$ & $(0.018)$ & $0.195 * * *$ & $(0.018)$ \\
\hline Balcony cabin & $0.444 * * *$ & $(0.019)$ & $0.444 * * *$ & $(0.019)$ \\
\hline Suite & $0.846^{* * *}$ & $(0.022)$ & $0.848^{* * *}$ & $(0.022)$ \\
\hline Cabin square footage (log of) & $0.081 * * *$ & $(0.015)$ & $0.079 * * *$ & $(0.015)$ \\
\hline Private bath & $0.111^{* * *}$ & $(0.030)$ & $0.108 * * *$ & $(0.029)$ \\
\hline Air conditioning & $0.048^{* *}$ & $(0.019)$ & $0.049 * * *$ & $(0.018)$ \\
\hline Refrigerator & 0.028 & $(0.017)$ & $0.033 * *$ & $(0.017)$ \\
\hline Individual safe & -0.006 & $(0.021)$ & & \\
\hline TV & -0.015 & $(0.038)$ & & \\
\hline Music console & 0.022 & $(0.019)$ & & \\
\hline Telephone & -0.000 & $(0.026)$ & & \\
\hline Hair dryer & $-0.046^{*}$ & $(0.024)$ & $-0.047 * *$ & $(0.022)$ \\
\hline
\end{tabular}

\footnotetext{
${ }^{12}$ The estimated coefficients of these variables are therefore price elasticities. Given that the variable excursions per night assumes the value 0 for some observations and that the logarithm is not defined at 0 , we add 0.001 to this variable before taking logs.

${ }^{13}$ Among the diverse models we tested, we also considered interactions between cabin type and other variables to see if different quality levels in the cabins would have an effect on the evaluations of other characteristics. However, the interactions were not significant. The results presented in Table 2 are robust to these specifications (the significant variables we find continue to be significant and with the same sign). A previous specification also included the variable tonnage of the ship. As tonnage (log of) resulted in high collinearity with capacity (log of) in the VIF test, we decided to include only capacity as the measure of size in the final analysis. The results of these various model specifications are available from the authors upon request.
} 


\begin{tabular}{|c|c|c|c|c|}
\hline \multirow[b]{2}{*}{ Age (log of) } & \multicolumn{4}{|c|}{ Ship characteristics } \\
\hline & $-0.085^{* * *}$ & $(0.015)$ & $-0.082 * * *$ & $(0.014)$ \\
\hline Capacity (log of) & $-0.199 * * *$ & $(0.020)$ & $-0.200 * * *$ & $(0.020)$ \\
\hline \multirow[t]{2}{*}{ Speed (log of) } & $-0.293 * * *$ & $(0.092)$ & $-0.293 * * *$ & $(0.090)$ \\
\hline & \multicolumn{4}{|c|}{ Trip characteristics } \\
\hline Nights (log of) & $-0.064 * * *$ & $(0.018)$ & $-0.072 * * *$ & $(0.018)$ \\
\hline Destination & \multicolumn{2}{|c|}{$F(14,1993)=8.73^{* * *}$} & \multicolumn{2}{|c|}{$F(14,2011)=9.27 * * *$} \\
\hline Cruise line & \multicolumn{2}{|c|}{$F(25,1993)=38.86^{* * *}$} & \multicolumn{2}{|c|}{$F(25,2011)=41.22 * * *$} \\
\hline Constant & $6.978 * * *$ & $(0.261)$ & $6.922 * * *$ & $(0.244)$ \\
\hline Number of obs & \multicolumn{2}{|c|}{2060} & \multicolumn{2}{|c|}{2072} \\
\hline Regression test & \multicolumn{2}{|c|}{$F(66,1993)=93.70 * * *$} & \multicolumn{2}{|c|}{$F(60,2011)=103.27 * * *$} \\
\hline Adjusted $\mathrm{R}^{2}$ & \multicolumn{2}{|c|}{0.7482} & \multicolumn{2}{|c|}{0.7477} \\
\hline Mean VIF & \multicolumn{2}{|c|}{2.01} & \multicolumn{2}{|c|}{1.96} \\
\hline Ramsey RESET test & \multicolumn{2}{|c|}{$F(3,1990)=0.79$} & \multicolumn{2}{|c|}{$F(3,2008)=0.61$} \\
\hline Heteroscedasticity Breusch-Pagan/Cook-Weisberg test & \multicolumn{2}{|c|}{$\chi^{2}(1)=1.88$} & \multicolumn{2}{|c|}{$\chi^{2}(1)=1.47$} \\
\hline
\end{tabular}

The results for the add-on variables are broadly consistent with the prediction of the model. Let us consider first add-ons that are not included in the cruise ticket variable. For on-board activities, we find the expected negative effect for casino, boutiques, Wi-Fi and beauty salon (statistically significant only in the parsimonious model, while the laundry service dummy variable is negative but not significant). The effect for the casino variable is particularly strong: the presence of a casino on the ship leads to a reduction of $28.5 \%$ in the ticket price. The spa dummy has instead an unexpected positive sign. For onshore excursions, we observe a positive coefficient, in line with the supposed low market power of cruise firms in this case. Finally, add-ons which are included in the ticket price exhibit a positive coefficient in the case of library and fitness (as predicted), while the swimming pool variable is not significant. The jogging track variable, instead, is significant but with a negative coefficient, against our prediction.

We now briefly comment on the results for control variables. As with the cabin characteristics, the estimation results confirm that cabin type is a significant determinant of cruise pricing. The $F$ test on the battery of dummies for this categorical variable shows that they are jointly significant. If we look at the estimated coefficients, we can see that suite and then balcony cabin are the most expensive types of cabin also in a ceteris paribus analysis. Another 
interesting result is that a $10 \%$ increase in the cabin square footage translates into a $0.8 \%$ increase in the price per night. Moreover, of the cabin characteristics, a private bath, air conditioning and refrigerator are the characteristics that have a significant positive effect on the price per night of a cruise. As for ship characteristics, older and bigger ships are characterised by lower prices, probably because of a perception of lower quality and economies of scale. The negative coefficient of speed can be justified by customers' preference for "quiet" trips rather than long-distance travel. Among the trip characteristics, the significant negative coefficient of the number of nights points to a scale effect and a quantity discount. Finally, the jointly significant destination and cruise line dummies correct for possible omitted variables that are constant over destinations and lines.

\section{Discussion}

Our theoretical results, with the support of the empirical evidence, provide new insights into add-on pricing by looking at the degree of market power and firms' asymmetries. In this section, we further elaborate on the implications of our results.

A first point refers to the evolution of pricing strategies in the presence of innovation and imitation in add-ons. When firms innovate by introducing a new add-on, they can obtain a competitive advantage irrespective of the degree of market power over the add-on. However, the pricing strategy of the innovator is affected by the degree of market power over the addon: when it is sufficiently low, the price for the baseline product increases. When the innovation is diffused, it is the baseline product price that declines, with firms obtaining their profits from the add-on. In a fascinating account of the razor industry, Picker (2011) shows that Gillette was in fact fixing a high price for razors (and a relatively low price for blades) during the monopoly period following the patented introduction of safety razors. Picker argues that Gillette's ability to fix a high price for blades was limited by the consumers' alternative to 
re-sharpen blades as they were used with straight razors. Instead, the add-on pricing strategy (also known as the "razor and blades" strategy) emerges only with competition.

A second point concerns firms' incentives to increase the degree of market power over addons. In the basic version of the model with full rationality, we found that profits are unaffected by the degree of market power. However, in presence of consumers with biased beliefs, for a given perception of add-on surplus, the increase in market power has a positive effect on profits (and makes the add-on strategy strictly preferred to bundling). In fact, firms seem to invest in increasing $\alpha$. In the cruise industry, for instance, the Norwegian Cruise Line introduced on-shore excursions to privately owned islands, from which the company appropriates all the revenues (Klein, 2006). It should be noted, however, that if consumers can learn the real value of $\alpha$ over time, the gain of the add-on pricing strategy reduces. Therefore, we can expect cycles in the introduction of add-ons, with firms continuously introducing new (high margin) add-ons, profiting from them until consumers assess the real surplus they can obtain from them. This argument has already been put forth by Gabaix and Laibson (2006).

\section{Conclusion}

The conventional wisdom on add-on pricing is that firms offering add-ons should unambiguously lower the price of the baseline product and obtain most of their profit from the add-ons. In this paper, we have shown that this conclusion is not warranted in asymmetric configurations, in which a single firm offers the add-on. In this case, the add-on is both a source of competitive advantage (because it increases product quality) and of additional revenues. When market power in the supply of the add-on is limited, the first effect prevails and baseline product prices are higher for firms offering the add-on. Our theoretical results find support in the empirical analysis. By estimating a hedonic price function on a dataset of cruises, we found that those additional activities that are characterised by high market power 
(i.e. on-board sales) reduce ticket prices, while the opposite occurs for low market power activities (e.g. shore excursions).

We see opportunities to build on our work in two directions. First, the implications for antitrust and consumer policy should be assessed. The current framework with discrete demand is not well suited to this, so an extension is needed. Second, one might consider building a model able to rationalise heterogeneity in pricing strategies even when all firms offer the add-on. For instance, in the game console market, Microsoft Xbox and Sony PlayStation are consoles usually priced below their cost, so that Microsoft and Sony have to recoup their investments with high prices for add-ons such as joypads (hardware) and games (software). Nintendo Wii, with a different strategy, produces consoles technologically less cutting edge that allow a positive profit (as the price for the base product is high in comparison to the cost). At the same time, prices for Nintendo Wii add-ons are usually lower (online gaming is free with Wii, whereas you have to pay a subscription with Xbox and PlayStation). ${ }^{14}$ Such a model would probably require more dimensions of consumers' heterogeneity (including their degree of sophistication) and appears to be an intriguing avenue for future research.

\section{References}

Alan, S., Cemalc1lar, M., Karlan, D., Zinman, J., 2015. Unshrouding Effects on Demand for a Costly Add-on: Evidence from Bank Overdrafts in Turkey (Working Paper No. 20956). National Bureau of Economic Research.

Borenstein, S., Mackie-Mason, J.K., Netz, J.S., 2000. Exercising Market Power in Proprietary Aftermarkets. J. Econ. Manag. Strategy 9, 157-188.

Brown, J., Hossain, T., Morgan, J., 2010. Shrouded Attributes and Information Suppression: Evidence from the Field. Q. J. Econ. 125, 859-876.

\footnotetext{
${ }^{14}$ http://www.vgchartz.com/
} 
Cabral, L., 2014. Aftermarket Power and Foremarket Competition. Int. J. Ind. Organ. 35, 60-69.

Carlton, D.W., Waldman, M., 2009. Competition, Monopoly, and Aftermarkets. J. Law Econ. Organ.

Chetty, R., Looney, A., Kroft, K., 2009. Salience and Taxation: Theory and Evidence. Am. Econ. Rev. $99,1145-1177$.

Ellison, G., 2005. A Model of Add-On Pricing. Q. J. Econ. 120, 585-637.

Ellison, G., Ellison, S.F., 2009. Search, Obfuscation, and Price Elasticities on the Internet. Econometrica 77, 427-452.

Gabaix, X., Laibson, D., 2006. Shrouded Attributes, Consumer Myopia, and Information Suppression in Competitive Markets. Q. J. Econ. 121, 505-540.

Hartmann, W.R., Nair, H.S., 2009. Retail Competition and the Dynamics of Demand for Tied Goods. Mark. Sci. 29, 366-386.

Kalayc1, K., Potters, J., 2011. Buyer Confusion and Market Prices. Int. J. Ind. Organ., Special Issue: Experiments in Industrial Organization 29, 14-22.

Klein, R.A., 2006. Turning Water into Money: The Economics of the Cruise Industry, in: Dowling, R.K. (Ed.), Cruise Ship Tourism. CABI Publishing.

Lal, R., Matutes, C., 1994. Retail Pricing and Advertising Strategies. J. Bus. 67, 345-370.

Normann, H.-T., Wenzel, T., 2013. Shrouding Add-on Information: An Experimental Study. Universitat Dusseldorf.

Picker, R.C., 2011. The Razors-and-Blades Myth(s). Univ. Chic. Law Rev. 78, 225-255.

Rosen, S., 1974. Hedonic Prices and Implicit Markets: Product Differentiation in Pure Competition. J. Polit. Econ. 82, 34-55.

Shapiro, C., 1995. Aftermarkets and Consumer Welfare: Making Sense of Kodak. Antitrust Law J. 63, $483-511$. 
Shulman, J.D., Geng, X., 2012. Add-on Pricing by Asymmetric Firms. Manag. Sci. 59, 899-917.

Spiegler, R., 2011. Bounded Rationality and Industrial Organization. Oxford University Press.

Verboven, F., 1999. Product Line Rivalry and Market Segmentation - with an Application to Automobile Optional Engine Pricing. J. Ind. Econ. 47, 399-425.

Vogel, M.P., 2009. On-board Revenue: The Secret of the Cruise Industry's Success? in: Papathanassis, A. (Ed.), Cruise Sector Growth. Gabler, pp. 3-15.

Vogel, M.P., 2011. Monopolies at Sea: The Role of On-board Sales for the Cruise Industry's Growth and Profitability, in: Matias, Á., Nijkamp, P., Sarmento, M. (Eds.), Tourism Economics. Physica-Verlag HD, pp. 211-229.

Walters, R.G., MacKenzie, S.B., 1988. A Structural Equations Analysis of the Impact of Price Promotions on Store Performance. J. Mark. Res. 25, 51-63.

Wenzel, T., 2014. Consumer Myopia, Competition and the Incentives to Unshroud Add-on Information. J. Econ. Behav. Organ. 98, 89-96.

Zegners, D., Kretschmer, T., 2014. Why Aftermarket Power Can Be Bad for Firms (SSRN Scholarly Paper No. ID 2236121). Social Science Research Network, Rochester, NY.

Zenger, H., 2013. Why Firms' Exploitation of Consumer Myopia May Benefit Myopic Consumers. Econ. Lett. 118, 307-309. 


\section{Appendix A}

\section{Proof of Proposition 1}

We now show how equilibrium prices are computed in each case.

\section{$\underline{\text { Case } a)}$}

If no firm offers A, consumers' utility functions are given by:

$$
\begin{aligned}
& u_{i}(0)=u^{B}-p_{0}^{B}-t x_{i} \\
& u_{i}(1)=u^{B}-p_{1}^{B}-t\left(1-x_{i}\right)
\end{aligned}
$$

The location of the indifferent consumer (for a given price) is obtained by solving:

$$
u^{B}-p_{0}^{B}-t \hat{x}=u^{B}-p_{1}^{B}-t(1-\hat{x})
$$

which yields:

$$
\hat{x}=\frac{1}{2}+\frac{p_{1}^{B}-p_{0}^{B}}{2 t}
$$

Demand for firm 0 is then equal to $\hat{x}$, while demand for 1 is equal to $1-\hat{x}$. Profit functions are thus as follows:

$$
\begin{aligned}
& \Pi_{0}=\left(\frac{1}{2}+\frac{p_{1}^{B}-p_{0}^{B}}{2 t}\right) p_{0}^{B} \\
& \Pi_{1}=\left(\frac{1}{2}+\frac{p_{0}^{B}-p_{1}^{B}}{2 t}\right) p_{1}^{B}
\end{aligned}
$$

As the two firms are symmetric, we need to consider the first-order condition of one firm only, say firm 0:

$$
\left(\frac{1}{2}+\frac{p_{1}^{B}-p_{0}^{B}}{2 t}\right)-\frac{1}{2 t} p_{0}^{B}=0
$$


Imposing symmetry $\left(p_{1}^{B}=p_{0}^{B}\right)$ and solving equation (A7), we obtain equilibrium prices $p_{1}^{B}=p_{0}^{B}=t$. Putting equilibrium prices into (A5) and (A6) yields the equilibrium profits.

\section{$\underline{\text { Case } b)}$}

If only firm 0 offers $\mathrm{A}$, the utility functions are:

$$
\begin{aligned}
& u_{i}(0)=(1-\alpha) u^{A}+u^{B}-p_{0}^{B}-t x_{i} \\
& u_{i}(1)=u^{B}-p_{1}^{B}-t\left(1-x_{i}\right)
\end{aligned}
$$

The location of the indifferent consumer (for a given price) is obtained, in this case, by solving:

$$
(1-\alpha) u^{A}+u^{B}-p_{0}^{B}-t x_{i}=u^{B}-p_{1}^{B}-t\left(1-x_{i}\right)
$$

which yields:

$$
\hat{x}=\left(\frac{1-\alpha}{2 t}\right) u^{A}+\frac{1}{2}+\frac{p_{1}^{B}-p_{0}^{B}}{2 t}
$$

Profits are given by:

$$
\begin{aligned}
& \Pi_{0}=\left(\frac{1-\alpha}{2 t} u^{A}+\frac{1}{2}+\frac{p_{1}^{B}-p_{0}^{B}}{2 t}\right)\left(p_{0}^{B}+\alpha u^{A}\right) \\
& \Pi_{1}=\left(\frac{\alpha-1}{2 t} u^{A}+\frac{1}{2}+\frac{p_{0}^{B}-p_{1}^{B}}{2 t}\right) p_{1}^{B}
\end{aligned}
$$

From the first-order conditions, we obtain firms' best response functions:

$$
\begin{aligned}
& p_{0}^{B}=\frac{t+p_{1}^{B}+(1-2 \alpha) u^{A}}{2} \\
& p_{1}^{B}=\frac{t+p_{0}^{B}-(1-\alpha) u^{A}}{2}
\end{aligned}
$$

Solving (A14-A15) yields equilibrium prices. Substituting equilibrium prices into (A12) and (A13) yields equilibrium profits. 


\section{$\underline{\text { Case } c)}$}

The solution of case $c$ ) is symmetric to case $b$ ).

\section{$\underline{\text { Case } d)}$}

If both firms offer A, consumers' utility functions are given by:

$$
\begin{aligned}
& u_{i}(0)=(1-\alpha) u^{A}+u^{B}-p_{0}^{B}-t x_{i} \\
& u_{i}(1)=(1-\alpha) u^{A}+u^{B}-p_{1}^{B}-t\left(1-x_{i}\right)
\end{aligned}
$$

The location of the indifferent consumer (for a given price) is obtained by solving:

$$
(1-\alpha) u^{A}+u^{B}-p_{0}^{B}-t \hat{x}=(1-\alpha) u^{A}+u^{B}-p_{1}^{B}-t(1-\hat{x})
$$

which yields:

$$
\hat{x}=\frac{1}{2}+\frac{p_{1}^{B}-p_{0}^{B}}{2 t}
$$

Demand for firm 0 is then equal to $\hat{x}$, while demand for 1 is equal to $1-\hat{x}$. Profit functions are thus as follows:

$$
\begin{aligned}
& \Pi_{0}=\left(\frac{1}{2}+\frac{p_{1}^{B}-p_{0}^{B}}{2 t}\right)\left(p_{0}^{B}+\alpha u^{A}\right) \\
& \Pi_{1}=\left(\frac{1}{2}+\frac{p_{0}^{B}-p_{1}^{B}}{2 t}\right)\left(p_{1}^{B}+\alpha u^{A}\right)
\end{aligned}
$$

As the two firms are symmetric, we need to consider the first-order condition of one firm only, say firm 0:

$$
\left(\frac{1}{2}+\frac{p_{1}^{B}-p_{0}^{B}}{2 t}\right)-\frac{1}{2 t}\left(p_{0}^{B}+\alpha u^{A}\right)=0
$$


Imposing symmetry $\left(p_{1}^{B}=p_{0}^{B}\right)$ and solving equation (A22), we obtain equilibrium prices $p_{1}^{B}=p_{0}^{B}=t-\alpha u^{A}$. Putting equilibrium prices into (A20) and (A21) yields the equilibrium profits.

\section{Proof of Proposition 2}

The proof is almost immediate. If $k<\frac{1}{2} t-\left(t-\frac{u^{A}}{3}\right)\left[\frac{1}{2}-\frac{u^{A}}{6 t}\right]$ (which, as can easily be verified, implies $\left.k<\left(t+\frac{u^{A}}{3}\right)\left[\frac{1}{2}+\frac{u^{A}}{6 t}\right]-\frac{t}{2}\right)$, OffA is the dominant strategy. If $k>\left[t+\frac{u^{A}}{3}\right]\left[\frac{1}{2}-\frac{u^{A}}{6 t}\right]-\frac{t}{2}$ (which implies $\left.k>\frac{1}{2} t-\left(t-\frac{u^{A}}{3}\right)\left[\frac{1}{2}-\frac{u^{A}}{6 t}\right]\right)$, NotOffA is the dominant strategy. If $\frac{1}{2} \mathrm{t}-$ $\left(\mathrm{t}-\frac{u^{A}}{3}\right)\left[\frac{1}{2}-\frac{u^{A}}{6 \mathrm{t}}\right]<k<\left[\mathrm{t}+\frac{u^{A}}{3}\right]\left[\frac{1}{2}+\frac{u^{A}}{6 \mathrm{t}}\right]-\frac{1}{2} \mathrm{t}$, OffA is the best response to NotOffA and vice versa, which leads to (symmetric) equilibria. 


\section{Appendix B}

Table B1 - Descriptive statistics

\begin{tabular}{|c|c|c|c|c|}
\hline Variable & Mean & Std Dev & Min & $\operatorname{Max}$ \\
\hline Price per night & 263.087 & 179.439 & 33 & 1490.833 \\
\hline \multicolumn{5}{|c|}{ Cabin characteristics } \\
\hline \multicolumn{5}{|l|}{ Cabin type } \\
\hline Inside cabin & 0.250 & 0.433 & 0 & 1 \\
\hline Ocean view cabin & 0.251 & 0.434 & 0 & 1 \\
\hline Balcony cabin & 0.249 & 0.432 & 0 & 1 \\
\hline Suite & 0.250 & 0.433 & 0 & 1 \\
\hline Cabin square footage & 222.483 & 132.608 & 12 & 2000 \\
\hline Private bath & 0.930 & 0.256 & 0 & 1 \\
\hline Air conditioning & 0.591 & 0.492 & 0 & 1 \\
\hline Refrigerator & 0.711 & 0.453 & 0 & 1 \\
\hline Individual safe & 0.758 & 0.428 & 0 & 1 \\
\hline TV & 0.941 & 0.236 & 0 & 1 \\
\hline Music console & 0.204 & 0.403 & 0 & 1 \\
\hline Telephone & 0.824 & 0.381 & 0 & 1 \\
\hline Hair dryer & 0.843 & 0.364 & 0 & 1 \\
\hline \multicolumn{5}{|c|}{ Ship characteristics } \\
\hline Laundry & 0.855 & 0.352 & 0 & 1 \\
\hline Swimming pool & 0.990 & 0.098 & 0 & 1 \\
\hline Beauty salon & 0.885 & 0.320 & 0 & 1 \\
\hline Casino & 0.925 & 0.263 & 0 & 1 \\
\hline Fitness & 0.815 & 0.388 & 0 & 1 \\
\hline Jogging track & 0.531 & 0.499 & 0 & 1 \\
\hline Boutiques & 0.792 & 0.406 & 0 & 1 \\
\hline $\mathrm{Wi}-\mathrm{Fi}$ & 0.531 & 0.499 & 0 & 1 \\
\hline Library & 0.800 & 0.400 & 0 & 1 \\
\hline Spa & 0.958 & 0.201 & 0 & 1 \\
\hline Age & 11.676 & 5.956 & 1 & 42 \\
\hline Capacity & 2455.823 & 1071.267 & 30 & 8994 \\
\hline Speed & 22.221 & 2.887 & 9 & 30 \\
\hline \multicolumn{5}{|c|}{ Trip characteristics } \\
\hline Nights & 7.894 & 4.058 & 1 & 33 \\
\hline Excursions per night & 0.617 & 0.267 & 0 & 2 \\
\hline \multicolumn{5}{|l|}{ Destination } \\
\hline Caribbean/Bahamas & 0.121 & 0.326 & 0 & 1 \\
\hline Alaska & 0.164 & 0.370 & 0 & 1 \\
\hline Australia/New Zealand & 0.006 & 0.076 & 0 & 1 \\
\hline Bermuda & 0.033 & 0.178 & 0 & 1 \\
\hline Europe-Northern & 0.192 & 0.394 & 0 & 1 \\
\hline Europe-Southern & 0.189 & 0.391 & 0 & 1 \\
\hline Europe-Rivers & 0.011 & 0.105 & 0 & 1 \\
\hline Hawaii/Tahiti/S. Pacific & 0.035 & 0.183 & 0 & 1 \\
\hline Mexico-Pacific Coast & 0.014 & 0.119 & 0 & 1 \\
\hline Asia/Africa/M.E. & 0.053 & 0.223 & 0 & 1 \\
\hline Panama Canal \& C. America & 0.016 & 0.125 & 0 & 1 \\
\hline South America & 0.006 & 0.076 & 0 & 1 \\
\hline US \& Canada Eastern & 0.049 & 0.216 & 0 & 1 \\
\hline US \& Canada Pacific & 0.017 & 0.131 & 0 & 1 \\
\hline Other & 0.095 & 0.293 & 0 & 1 \\
\hline \multicolumn{5}{|l|}{ Cruise line } \\
\hline Carnival Cruise & 0.090 & 0.286 & 0 & 1 \\
\hline Costa Cruise & 0.068 & 0.252 & 0 & 1 \\
\hline Disney Cruise Line & 0.034 & 0.181 & 0 & 1 \\
\hline MSC Cruises & 0.077 & 0.267 & 0 & 1 \\
\hline Norwegian Cruise Line & 0.085 & 0.279 & 0 & 1 \\
\hline Princess Cruises & 0.083 & 0.276 & 0 & 1 \\
\hline Royal Caribbean International & 0.123 & 0.328 & 0 & 1 \\
\hline
\end{tabular}




\begin{tabular}{lllll} 
Azamara Club Cruises & 0.048 & 0.214 & 0 & 1 \\
Celebrity Cruises & 0.091 & 0.287 & 0 & 1 \\
Cunard Line & 0.078 & 0.268 & 0 & 1 \\
Holland America Line & 0.046 & 0.210 & 0 & 1 \\
Oceania Cruises & 0.052 & 0.222 & 0 & 1 \\
Crystal Cruises & 0.009 & 0.093 & 0 & 1 \\
Regent Seven Seas Cruises & 0.002 & 0.044 & 0 & 1 \\
Seabourn & 0.002 & 0.044 & 0 & 1 \\
SeaDream Yacht Club & 0.002 & 0.044 & 0 & 1 \\
Silversea & 0.004 & 0.062 & 0 & 1 \\
Star Clippers & 0.012 & 0.107 & 0 & 1 \\
Windstar Cruises & 0.004 & 0.062 & 0 & 1 \\
AmaWaterways & 0.004 & 0.062 & 0 & 1 \\
American Cruise Lines & 0.007 & 0.085 & 0 & 1 \\
American Safari Cruises & 0.003 & 0.058 & 0 & 1 \\
Avalon Waterways & 0.006 & 0.076 & 0 & 1 \\
Uniworld River Cruises & 0.006 & 0.076 & 0 & 1 \\
Viking River Cruises & 0.006 & 0.076 & 0 & 1 \\
Other & 0.060 & 0.237 & 0 & 1 \\
\hline
\end{tabular}

Source: Cruise.com 


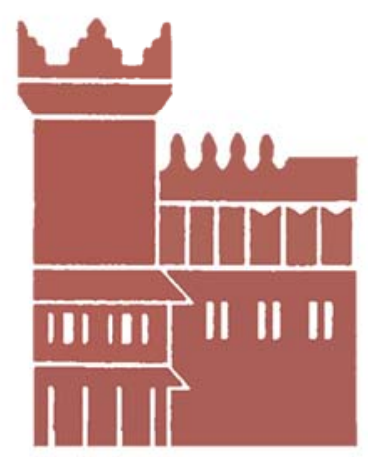

Alma Mater Studiorum - Università di Bologna DEPARTMENT OF ECONOMICS

Strada Maggiore 45

40125 Bologna - Italy

Tel. +39051 2092604

Fax +390512092664

http://www.dse.unibo.it 